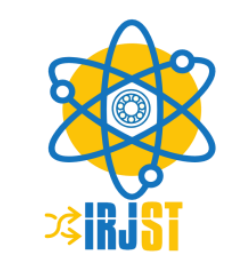

Available online at https://www.irjst.com/

International Research Journal of Science and Technology

ISSN: 2707-3955

DOI: https://doi.org/10.46378/irjst.2021.020302

\title{
Opinion of Recruiters About the Role of Physical Attractiveness in the Process of Selection: Qualitative study.
}

\author{
Naveeda Sarwar ${ }^{1 *}$, Muhammad Jahanzeb Khan ${ }^{2}$, Adnan Sarwar ${ }^{3}$, Saima Abid ${ }^{4}$, Humaira Ali ${ }^{5}$ \\ ${ }^{1 *}$ Psychologist, Research Supervisor PhD scholar in Psychology, University of Peshawar, Pakistan \\ ${ }^{2}$ Professor, Vice Chancellor, Fata University, Pakistan \\ ${ }^{3}$ Assistan Professor (Hematology), Pak International Medical College, Peshawar, Pakistan \\ ${ }^{4}$ Associate Professor (Public Health), Pak International Medical College, Peshawar, Pakistan \\ ${ }^{5}$ Lecturer Psychology, Swabi Women University. Pakistan
}

\begin{tabular}{lll}
\multicolumn{2}{l}{ Paper Status } & \\
Received : & Arp 2021 \\
Accepted : & Jun 2021 \\
Published : & Jun 2021
\end{tabular}

Key Words

Phenomenology,

Physical Attractiveness

Purposive Sampling

Recruiters

\begin{abstract}
Attractive people often take an advantage in their life and offer preference over those who are unattractive. These problems may be ethical, cultural or social, but they may also Important impacts on the recruiting process and maybe key to problems discrimination. The present study describing the phenomena of physical attractiveness ensures effects the recruitment process with some of the basic condition outline in the implicit personality theory. The sample size was constituted 20 and saturated on the 10 of participants (6 males and 4 female) phenomenology: Non - probability Purposive sampling technique was used. Those participants were involved as the leading recruiter such as director, cos', selection board member and principal of institutes as these were from hospitals, education institutes, Ngos and local government and ruler department in order to ensure maximum variation sampling technique as them belong to different heads of institutes. The data was collected through in depth interview by using semi-structure open ended questionnaire. These phases were: familiarization with data, generating initial codes, searching for themes among codes, reviewing themes, defining and naming themes and producing the final report were analyzed. Five themes were emerged as a results of the study, each themes were individually discussed to comprehend over its meaningful features, Performa for hiring candidate's, Gender preferences according to the job status, Communication and Confidence level, Knowledge about the Desired Field and Qualification and Experiences. It was concluded from the respondents interview that physical attractiveness has important impact for the selection of employ whether government organization or nongovernment organization.
\end{abstract}

Copyright () 2021: Naveeda Sarwar, Muhammad Jahanzeb Khan, Adnan Sarwar, Saima Abid, Humaira Ali. This is an open-access distribution, and reproduction in any medium provided Access article distributed under the Creative Commons Attribution License the original work is properly cited License, which permits unrestricted use.

Citation: Naveeda Sarwar, Muhammad Jahanzeb Khan, Adnan Sarwar, Saima Abid, Humaira Ali. “Opinion of Recruiters About the Role of Physical Attractiveness in the Process of Selection: Qualitative study ”, 2 (3), 433-439, 2021.

\section{Introduction}

In today's organizations, the problems adjoining identifying and hiring the best workers are growing complicated day by day. One of the causes is the decline in the number of people Capable applicants and rising global economic complications.

\footnotetext{
* Corresponding Author: Naveeda Sarwar

Psychologist, University of Peshawar, Pakistan

Email: naveedasarwar6@gmail.com
}

There could be another explanation. Discrimination against the applicants by employers. There are also various secret problems can impact other than qualification and experience recruitment and selection procedure, Of candidates. These problems may be ethical, cultural or social, but they may also Important impacts on the recruiting process and maybe key to problems discrimination. Those organizations that do not know the value of these are likely to Problems 
concerning the physics, dressing style, gender, ability, race, Communication skills or looks may be involved in activities based on some kind of racism.

In its popular research report, called "What is Great is Good," concluded that attractive people often take an advantage in their life and offer preference over those who are unattractive [1]. stereotyping occurs when constructive individual characteristics are attributed to individuals as per their physical attractiveness [2]. The theory of implicit personality (1994) is studied by Pendry and Macrae ([3], [4]). The recipients attach a number of qualities of identity to the individual once a man is assigned to appeal or not to appeal. Theoretical implied the implicit personality theory perspective to considerate the physical attractiveness stereotype. They discussed that the social classifications "physically attractive"and "physically unattractive "are accompanying inferentially to variability of evaluative domain [5].

\section{Methodology}

Qualitative research with phenomenological study design was selected for the reason that "the phenomenologists are concerned with understanding social and psychological phenomena from the perspectives of people involved" [6] .So the present study describing the phenomena of physical attractiveness ensures effects the recruitment process with some of the basic condition outline in the implicit personality theory .The COREQ guidelines were followed to ensure all the significant domain of qualitative research were addressed. The sample size was constituted 20 and saturated on the 10 of participants (6 males and 4 female) phenomenology: five to 25 [7]; at least six [8]. Non - probability Purposive sampling technique was used. Those participants were involved as the leading recruiter such as director, cos', selection board member and principal of institutes as these were from hospitals, education institutes, Ngos and local government and ruler department in order to ensure maximum variation sampling technique as them belong to different heads of institutes. The data was collected through in depth interview by using semi-structure open ended questionnaire.

The informed consent was taken before conducting video-recording. The questionnaire based on two parts that's were demographic characteristics and proceed to open-ended questions in order to get comprehensive opinion of those recruiters. The validity of the question was checked through blind review of research cell by KMU (Khyber medical university). The data was analyzed by using Four main stages i-e the decontextualisation, the recontextualisation, the categorization, and the compilation.

\section{Results and Data Analysis}

For the our qualitative reserach the opinion of recuriters about physical attractiveness during the selection process were interview from the leading recuiters of an organization or institues.first, the reason behind the in -depth interview were explained to them .secondly the semi-struture questionaire design from the extensive literature review were video recoreded. Initial analysis was commenced by first cycle of coding i.e Open Coding. Second cycle of coding was done to find out relationships by axial coding. Then Thematic Analysis was done to create meaningful patterns. Thematic analysis was performed through the process of coding in six phases to create meaningful patterns. These phases were: familiarization with data, generating initial codes, searching for themes among codes, reviewing themes, defining and naming themes and producing the final report.

Table 1. Demographic Characteristics

\begin{tabular}{lll}
\hline Number of respondent & 10 & $100 \%$ \\
Male & 6 & $60 \%$ \\
Female & 4 & $40 \%$ \\
Professional background & & \\
Private Organizational official & 4 & $40 \%$ \\
Educational institute official & 4 & $40 \%$ \\
Government organizational official & 2 & $20 \%$ \\
\hline
\end{tabular}

\subsection{Creating a Report and Presentation of The Result}

The conceptualization map shows the presentation of the data set with different stages categorization. The two broad domain i-e manifest content and latent content were merge into one category because the manifest domain represent the same data as the latent content .so the in-depth semi -structure open ended questions were represented below through the tree map by the Rawgraph web. The results of nine in depth interviews were summarized based on thematic categorizations.

\subsubsection{Theme 1: Performa for hiring candidate's:}

All the participants in the study were illustrated that for recruitment process of any organization whether in hospital, colleges, non-profit Ngos and government organization there were specific proforma for an interview and that was design those institutes hiring personnel for the requirement of those candidate's. These proforma were the means to the road of physical attractiveness not as means of beatification but as ways of specific desired standards for any institutes require for those specific jobs. Some of the representative's statements of the interviewee are as per any selection process whether offices or hospitals or any educations institutes I think in every organization there is some specific godliness which you may call proforma or check list which has given to every recruiters and they 
mark them and in the end all the marks are compiled, yes off course there is some place for attractiveness as you may have called as styles of communication confidently way of presentable will take regarded" (interviewee no:3).

\subsubsection{Theme 2.Gender Preferences According to the Job Status}

All the participants in the study had clearly described selection of an employ as male or female. While during study it was cleared from the statements of the respondents that in Pakistan culture the male had more advantages but at same time status of the job would also be ascribed for gender. As per replied it was stated that male selection for those job whose offices are remote areas as compared to those fields female preference was given to the head office. Some of the representative statements: "it depends on the society for example we had to conduct filed like activities one has to go out and bez here in Khyber Pakhtunkhwa here is male dominating society, female are prefer to those kinds of job which is mostly office related and confined to one place, while male are prefer for filed going out and conduct desired jobs but depending on the type of job, that's is restricted or involving official works as my first preference will be female bases on the type of jobs we have to look into gender as wells"(interviewee no : 1)

\subsubsection{Theme 3. Communication and Confidence Level}

All the participants in the study emphasized that first impression in the context of hiring some candidates would best be standards through effective communication skills and confidence level how to present the requirement information presented in front of the interviewer which had been asked and which were included in the proforma. there is specific code dress for any selection process not as per rules of informal dressing.

Some of the illustration by interviewee is "look physical attractiveness so far any organization consider not as beautifications but during an interview he and she way of communication and confidence levels how might present their knowledge and grab focus of recruiters by engaging them full bloom of confidence and presenting knowledge." (interviewee no:4)

\subsubsection{Theme 4. Knowledge About the Desired Field}

All the respondents demonstrated that while hiring an individual whether government or non-government organization required knowledge and specialization of that specific field.it was also revealed from the data interview timing doesn't cover the knowledge of entire filed but few question of the related fields gives the impression that an employ had an ability to utilizes in practical filed rather mere as a bookish person.
Some of the statements by the respondents is "look as outfit or dressing little count during selection as one may not come for interview wearing bangles (female) or wearing causal chapel (male), there is some dress code in every organization to be followed as protocal,but so far as member of selection barad I might think not only my opinion but I think everyone while hiring employ there mostly credits given to their knowledge which had been asked during the interview mean sufficient application of knowledge to the desired filed according to his/her specialization" ( interviewer no:2 and 5).

\subsubsection{Theme 5.Qualification and Experiences}

It was illustrated that for selection of applicants in any filed whether doctors, teachers, government officers and project mangers the utmost priorities had been given to the qualifications and experiences .so far the interview process were conducted the maximum marks had been given to qualification and experiences rather than confidences and communication at that specific situation.

Following of the some of the statements of respondent is "as I think picture is only formality of cv and second off course if there is qualified and experience individual the vote is usually given to that one who had good communication but presenting his/her knowledge more confidently according to the situation". (Interviewee no:9 and 10).

\section{Discussion}

The current study demonstrated the opinion of recruiters about the role of physical attractiveness in the process of selection. From our analysis, it was quantifying from the interview of all the expert of selection boards member about physical attractiveness in their best possible experienced and perception discussed comprehensively. Five themes were emerged as a results of the study, each themes were individually discussed to comprehend over its meaningful features.

- Performa for hiring candidate's

- Gender preferences according to the job status

- Communication and Confidence level

- Knowledge About the Desired Field

- Qualification and Experiences

The participants very precisely shared their views regarding physical attractiveness during process of selection while it was stated by the results that all the organization leader or recruiters some basic tents of hiring candidates and these tents were described in the proforma. those Performa constituted not only the knowledge levels and experiences but the way of the respondents who present themselves during interview process. These proforma includes marks related to communication, way of presentation, knowledge, 


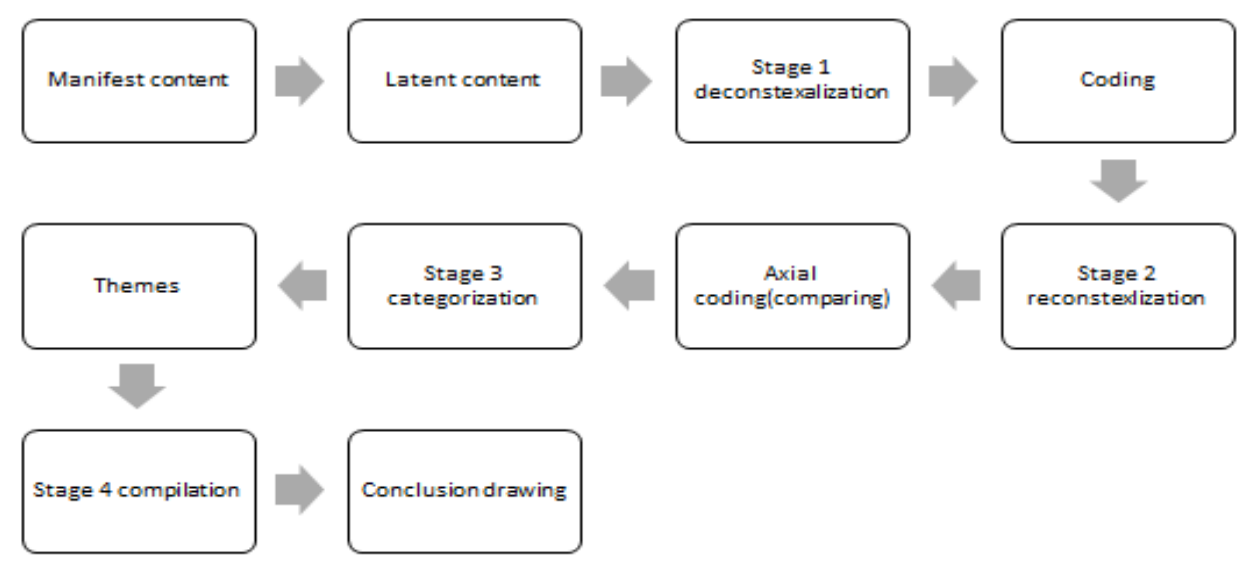

Figure 1. Conceptualization Map

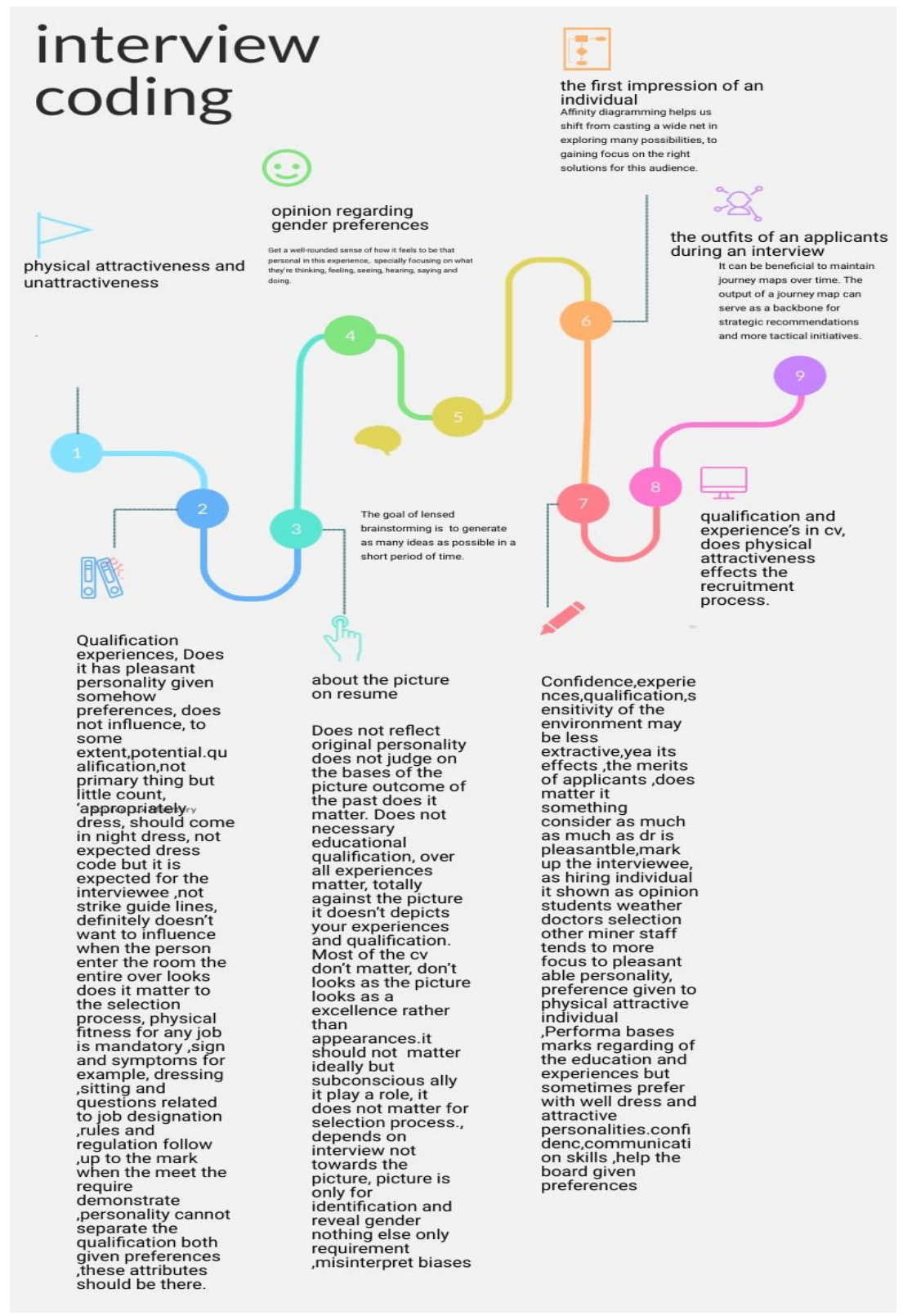

Figure 2. Stage 1. Intrview Coding 


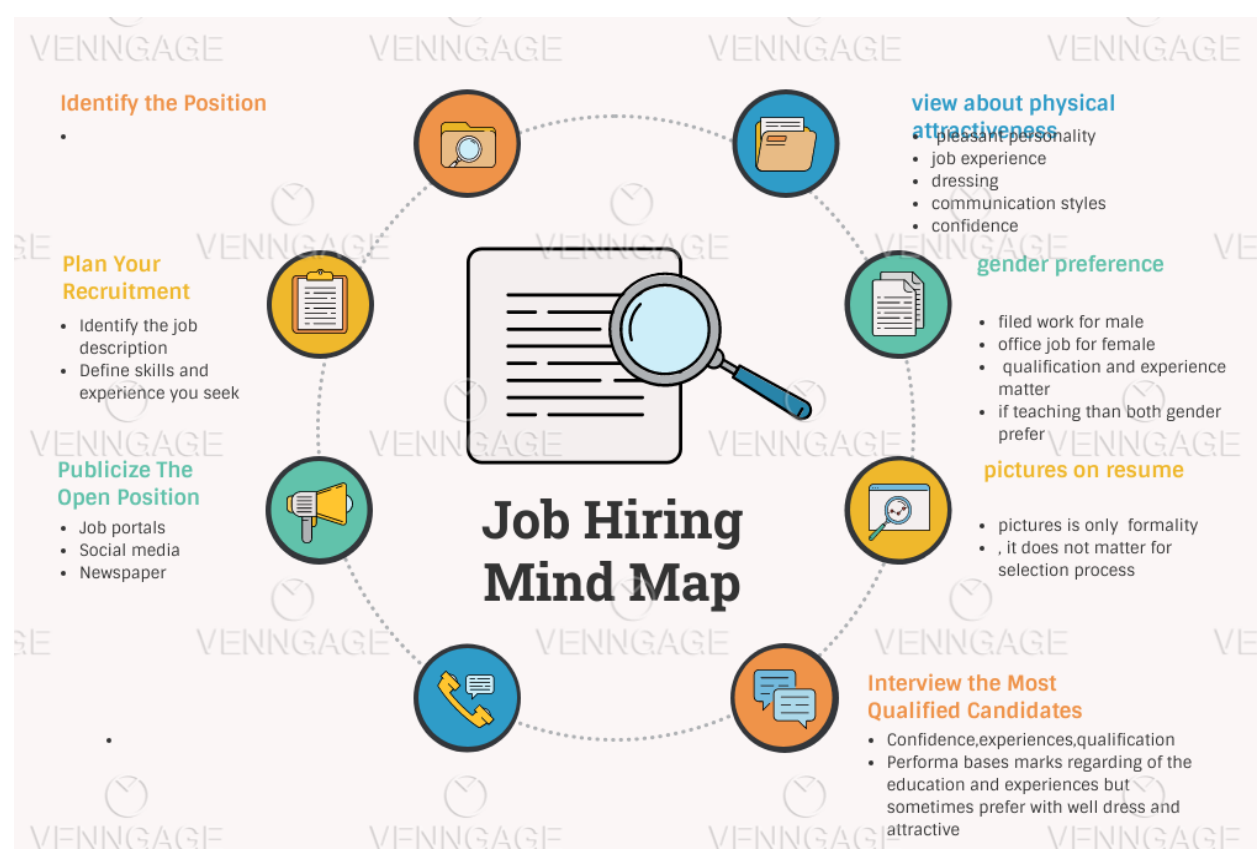

Figure 3. Stage 2.Recontexalization ( Axial coding)

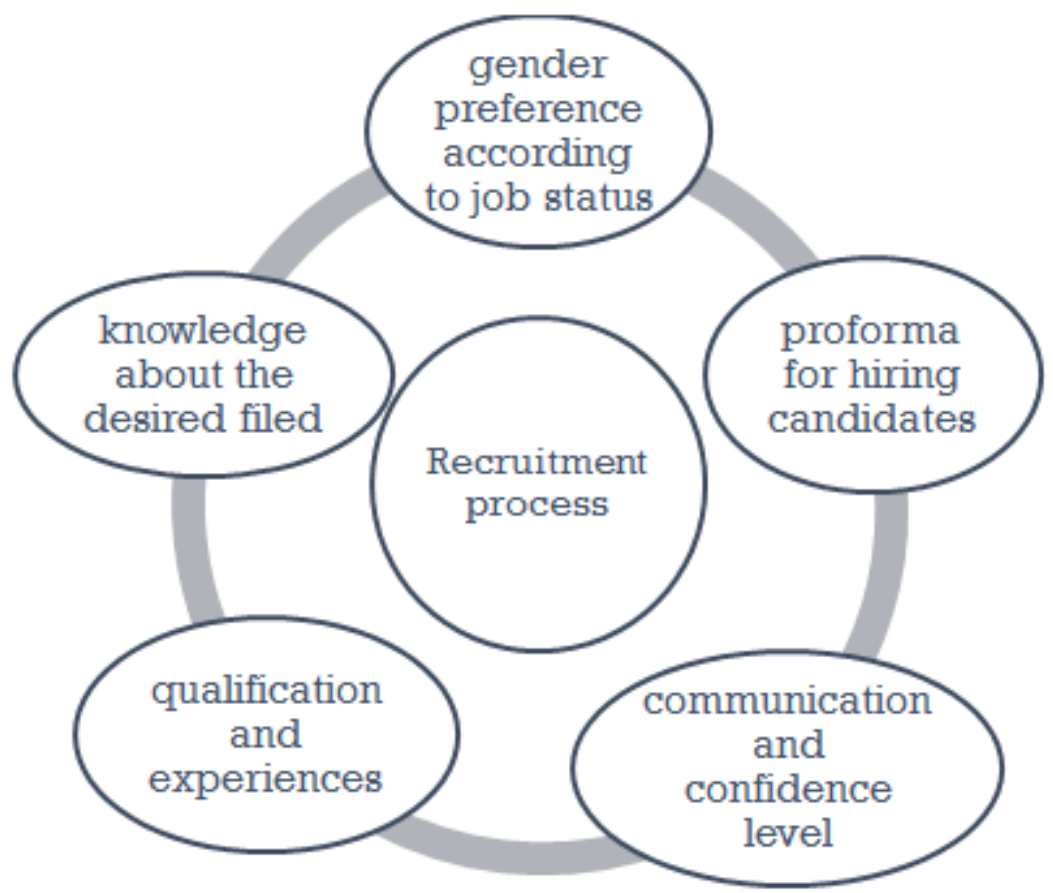

Figure 4. Stage 3.Categorization Theme

experiences, dressing, body language. According to Daniel Hamermesh, an economist at the University of Texas physically attractive workers make considerably higher salary than non-attractive workers during their lifetime [ 9.] Fortunately, this isn't the case with our interviewees. Appearance is considered as a part of a person's non-verbal communication; and it is linked directly to "attractiveness" and physical attractiveness is a "prized possession" as well as a valued one, as same the current research participant's communication is one of the basic components of attractiveness [10].
Research shows that there are significantly more wages and wage growth for both male and female as per their attraction rate. It is even found that attractive people are more appreciated, receives more help and cooperation than the unattractive ones. It is also concluded that wage premiums also reflect employer discrimination [11].while the present study interviwers views regarding gender prferences into some different perspectives.as the study was conduted in kayberpaktun khawa there is some limitation on jobs regarding gendr preferences e,g filed type jobs were more prfereed for male, while headoffice specificlly 
statatic nature female were given prioritites .while for teaching as well as doctors both gender given prferences as per their qualification and experiences. According to James (2008), appearance is considered as a part of a person's non-verbal communication; and it is linked directly to "attractiveness" and physical attractiveness is a "prized possession" as well as a valued one [10]. While the current study demonstrated that communication both verbal and nonverbal with appropriate standards of the specific cultural considered important for the recruitment process.it would through light on the confidence level. On the confidence level which considered the basic fundamental of any interviewee selection.

A physically attractive applicant will get hired over an unattractive applicant if both holding similar qualifications/CV or if they see different treatment based on physical appearance in the work place, the majority said that they do think an attractive applicant would be hired over an unattractive one if both have similar qualification/CV, however, they have not come across such discrimination based on their appearance and if they did, it would de-motivate the employees, which in turn could lead to decrease in productivity [12]. While the present study comprehensive views about qualification and experiences if both were same than attractive individuals were preferred as compared to nonattractive individuals.

The role of physical attractiveness quality in employment choices has become a solid research material, which has gotten a partial educational consideration. Physical attractiveness impacts in associations are all around [13]. Physically attractive people have gotten more positive assessments than unattractive people in employment, according to Marshall et al. (1998), in advancement [14,15,16,17]. While the present study which was conducted in Khyber Pakhtunkhwa and there was some boundaries and limitation as culture, the respondents demonstrated that while picture are important as cv prior criteria as being have any idea about male and female but it's not considered as much priorities as it was stated in the literature ,the same wattages had given to experiences and desired knowledge which was presented by the employ during day of interview it's not mere testing of their memory but only application of knowledge to professional fields.

So in all its sees that physical attractiveness is important as per employ knowledge, communication, proper dressing on day of interview, experiences, male and female job preferences selection as per their specific place.

The delimitation of the study is small sample saturation which need to included other provinces as well. The data cannot statistically representative for generalization of the whole population. Only in-depth interview was conducted their need to be for future research mixed study both qualitatively and quantatively be carried out.

\section{Conclusion}

It was concluded from the respondents interview that physical attractiveness has important impact for the selection of employ whether government organization or non-government organization.

\section{References}

[1]. Dion, K., Berscheid, E., \& Walster, E. (1972). What is beautiful is good. Journal of personality and social psychology, 24(3), 285.

[2]. Myers, D. G., \& Diener, E. (1995). Who is happy? Psychological science, 6(1), 10-19.

[3]. Ashmore, R. D., \& Del Boca, F. K. (1981). Sex stereotypes and implicit personality theory. In D. L. Hamilton (Ed.), Cognitive processes in stereotyping and intergroup behavior. Hillsdale, NJ: Erlbaum.

[4]. Pendry, L. F., \& Macrae, C. N. (1994). Stereotypes and mental life: The case of the motivated but thwarted tactician. Journal of Experimental Social Psychology, 30(4), 303325.

[5]. Eagly, A. H., Ashmore, R. D., Makhijani, M. G., \& Longo, L. C. (1991). What is beautiful is good, but...: A meta-analytic review of research on the physical attractiveness stereotype. Psychological bulletin, 110(1), 109.

[6]. Welman, J. C., Kruger, S. J. (1999). Research methodology for the business and administrative sciences. Johannesburg, South Africa: International Thompson.

[7]. Creswell, J. W. 2013. Qualitative inquiry and research design. Los Angeles, CA: Sage Publishers, Inc

[8]. Morse, Janice M. (1994). Designing funded qualitative research. In Norman K. Denzin \& Yvonna S. Lincoln (Eds.), Handbook of qualitative research (2nd ed., pp.220-35). Thousand Oaks, CA: Sage.

[9]. Cavico, F. J., Muffler, S. C., \& Mujtaba, B. G. (2012). Appearance Discrimination, Lookism And Lookphobia In The Workplace. Journal 
of Applied Business Research (JABR), 28(5), 791-802.

https://doi.org/10.19030/jabr.v28i5.722 3

[10]. Christensen, P., \& James, A. (Eds.). (2008). Research with children: Perspectives and practices. Routledge

[11]. Loh, E. S. (1993). The Economic Effects of Physical Appearance. Social Science Quarterly (University of Texas Press) , 74 (2), 420-438

[12]. Khalida, M. K \& Sabah, A.L. (2010). Applicants attractiveness: does physical appearance master in selection and recruitment process.UAE

[13]. . Hosoda, M., Stone-Romero, E. F., \& Coats, G. (2003). The Effects of Physical Attractiveness

[14]. On Job-Related Outcomes: A MetaAnalysis Of Experimental Studies. Personnel Psychology, 56 (2), 431462

[15]. Marshall, T. F. (1998). Restorative justice: An overview. Center for Restorative Justice \& Mediation.

[16]. Morrow, P. (1990). Physical attractiveness and selection decision making. Journal of Management , 16 (1), 45-60

[17]. Frieze, I. H., Olson, J. E., \& Russell, J. (1991). Attractiveness and income for men and women in management 1 . Journal of Applied Social Psychology, 21(13), 1039-1057. 